\title{
The Ultrastructure of Intradental Nerves in Developing Mouse Molars'
}

\author{
RICHARD E. CORPRON AND JAMES K. AVERY \\ School of Dentistry, University of Michigan, \\ Ann Arbor, Michigan 48104
}

\begin{abstract}
The purpose of this investigation was to study the nerves in mouse molar teeth during their development to observe their distribution and their relationship to the odontoblast and its process. The specimens were first assessed by light microscopy using silver staining techniques. It was found that by nine days after birth, major nerves appeared in the pulp organ and extended to the basal region of the odontoblasts. At 15 days, a subodontoblastic neural plexus had developed, and by 25 days, isolated nerves penetrated into the predentin of the pulpal horns. From 25-70 days, a highly organized subodontoblastic plexus was apparent with branches extending into the odontoblastic layer, predentin and inner dentin.

Ultrastructural study revealed small, nonmyelinated nerves at the basal region of the odontoblasts by nine days. Both myelinated and small, nonmyelinated nerves appeared in the subodontoblastic plexus. Small nerves closely associated with the odontoblastic process were found within the predentinal tubules by 25 days. These processes contained occasional mitochondria, numerous microvesicles and small dark granules. From 35-50 days of age, similar nerves which exhibited alternate constrictions and dilations along their lengths were found in the tubules of circumpulpal dentin. By 60 days, both Schwann cell covered and naked axons appeared among the odontoblasts, and by 70 days Schwann cell covered axons appeared in predentin.
\end{abstract}

The pattern of development of pulpal nerves has been observed by light microscopy in silver impregnated sections of teeth by Arwill ('58), Fearnhead ('57, '61), Kubota et al. ('60) and Bernick ('59a). Arwill ('58) utilized both silver and iron trioxyhematoxylin staining and observed no nerve fibers in developing dentin of 13-32 week old human fetuses nor in mineralized dentin of erupted human permanent teeth. A few nerve fibers were observed in predentin of the erupted teeth, but such fibers did not appear intratubular in location. Fearnhead ('57) reported that the subodontoblastic nerve plexus did not appear until root formation was nearly complete, and that innervation of coronal dentin followed only after the tooth had been in functional occlusion for several years.

Occasional nerve fibers in the predentin of human teeth have been reported by Fearnhead ('57, '61), Rapp et al. ('57),
Kubota et al. ('60), Kerebel ('64), Arwill ('60) and Bernick ('59b, '64). Fearnhead ('57) noted that small intratubular nerves about $0.2 \mu$ in diameter extended through the predentin and into the dentin for a short distance. In no instance were such nerves found to traverse the entire thickness of the dentin or terminate near the dentino-enamel junction. On the other hand, Stella and Fuentes ('65) reported intratubular nerves which terminated in the peripheral dentin. However they used iron hematoxylin which is a nonspecific stain for neural elements.

More recently, the increased magnification and resolution of the electron microscope have yielded further information concerning intradentinal nerves. Frank ('68b) identified intratubular nonmyeli-

Received July 24, '72. Accepted Oct. 17, '72.

1 This project was supported by USPHS Research grant DE 01604 from the National Institute of Dental Research, National Institutes of Health, Bethesda, Research, 
nated nerve fibers approximately $0.3-0.5 \mu$ in diameter in human dentin and noted their close approximation to the odontoblastic process in dentinal tubules. Frank ('68a) described occasional specialized intercellular complexes appearing between intratubular nerve endings and the surface membrane of adjacent odontoblastic processes in human teeth. Johansen ('67) reported nerve fibers located in the tubules of the predentin and at the predentindentin junction. Arwill ('67) observed structures similar to those reported by Frank ('68b) and labeled them "associated cells." The latter were found only in the predentin.

It was the initial purpose of this investigation to study the changes in the distribution of neural elements in the pulp during such stages of tooth formation as crown formation, eruption, functional occlusion and during aging. The other object of this study was to carefully examine the contents of the tubules of predentin and dentin to discern if they contain nerves and to assess possible changes in the relationship of these structures to the odontoblast and its process during the life of the tooth.

\section{METHODS AND MATERIALS}

First molars were obtained from SwissWebster white mice sacrificed at two day intervals at 1-25 days of age and sacrificed at five day intervals at 25-70 days of age. Each age group contained five animals. Both halves of the mandible were removed and the tissues for light microscopy were immediately fixed at $4^{\circ} \mathrm{C}$ for 12-35 hours in 10\% formalin buffered at pH 7.4. Following fixation, the specimens were washed and decalcified in $4 \mathrm{~N}$ formic acid. The specimens were then washed, dehydrated by passage through ascending grades of ethanol, and double embedded in parlodion. They next were cleared in benzene, embedded in Paraplast (Scientific Products, Evanston, Illinois), and oriented to attain both longitudinal and mesiodistal sections of the mandibular first molar. Serial sections were mounted from a gelatinized water bath and allowed to stand overnight at $37^{\circ} \mathrm{C}$, and silver stained by the Ungewitter method as modified by Rowles and Brain ('60). Silver stained sections were utilized to determine the location and relationship of the neural elements to the developing pulp and dentin.

The ultrastructural studies used the mandibular first molars from groups of five Swiss-Webster white mice sacrificed at daily intervals of 1-25 days of age, and from 25-70 days at five day intervals. Fixation was carried out using $1.33 \%$ osmic acid buffered with so-collidine at $\mathrm{pH}$ 7.4 with $5 \%$ sucrose added to obtain an isotonic solution. The apical one third of the roots was removed and the teeth were fixed for two hours at $4^{\circ} \mathrm{C}$. The specimens were next washed in distilled water, dehydrated in a series of graded ethyl alcohols, passed through two changes of propylene oxide, transferred to $50 \%$ propylene oxide and $50 \%$ Epon 812 , and finally embedded one hour later in Epon 812 in Beem Capsules. The blocks were placed in an oven at $37^{\circ} \mathrm{C}$ overnight, $45^{\circ} \mathrm{C}$ on the following day, and $60^{\circ} \mathrm{C}$ overnight. Thick sections $(1 \mu)$ were produced and stained with methylene blue for orientation, and ultrathin sections were prepared from the molars with an LKB ultramicrotome equipped with a DuPont diamond knife. The sections were stained with aqueous uranyl acetate and photographed with both an R.C.A.-EMU 3D and an Hitachi HS 8 electron microscope. Over 3,000 photographs were taken at original magnifications of from $2,000-43,500 \times$.

\section{RESULTS}

\section{Light microscopic observations}

Silver stained sections allowed sequential study of developmental patterms of nerves in the entire pulpal chamber of mouse molars. At one day after birth, initiation of predentin deposition was observed at the cuspal tips of the first molars, followed shortly by the deposition of enamel matrix. The dental papilla was devoid of nerves, but occasional blood vessels were observed at that age.

By five days, the central portion of the pulp contained several nerve trunks which were closely associated with blood vessels. The larger nerves divided into smaller branches that terminated some distance from the odontoblastic layer in the pulpal 
horns (fig. 1). The outline of the crown appeared to be about two-thirds complete by seven days. In the central area of the pulp, major nerve trunks closely approximated major vessels, and although there was no definite subodontoblastic neural plexus at nine days, occasional nerves appeared subadjacent to the odontoblastic layer and independent of nearby blood vessels (fig. 2). The cemento-enamel junction was established by eleven days, when initial cemental deposition appeared along the surface of the root. By 15 days, numerous nerves appeared subjacent to the odontoblastic layer and individual fibers branched and extended directly into the basal portion of the odontoblastic layer at the tip of the cuspal horns (fig. 3). The developing molars exhibited considerable growth in root length.

Eruption of the first molar occurred by 19 days at which time the subodontoblastic neural plexus had increased in density, especially at the pulpal horns. Additional lateral branches contributed extensively to the plexus from which numerous branches extended into the base of the odontoblastic layer (fig. 4). Functional occlusion occurred by 25 days and an occasional nerve fiber extended peripherally beyond the odontoblastic layer to loop into the predentin and terminate a short distance in the dentin at the tip of the pulpal horns (fig. 5). At this age, the intradentinal nerves extended up to $40 \mu$ into the dentin overlying the pulpal horns where the dentin at the cuspal tip measured a maximum of $350 \mu$.

From 25-70 days, the number of nerves comprising the subodontoblastic plexus of the coronal pulp tissue increased substantially. By 50 days, the distribution of intradentinal nerves was usually in limited clusters of nerves in the dentin overlying the pulpal horns (fig. 6), but infrequently a nerve could be traced into the lateral walls of the coronal dentin just below the pulpal horns or into the intercuspal dentin of the roof of the coronal chamber. Only rarely was an intradentinal nerve observed in the radicular dentin. Occasional beading of the intratubular nerves could be observed in predentin and in the periphery of the dentin (fig. 6). No intradentinal nerves could be detected peripheral to the inner one third of the coronal dentin of molars by 70 days.

\section{Ultrastructural observations}

Based on the information gained from the light microscopic observations which revealed the majority of the nerves to be located in the coronal pulp and dentin, the ultrastructural study was limited to this area in teeth from one through 70 days of age.

Both myelinated and small nonmyelinated nerves were present in the central pulp by five days, but none extended into the subodontoblastic regions until nine days, as had been noted with the light microscope observations. At nine days occasional small, nonmyelinated nerves (less than $2 \mu$ diameter) which retained their Schwann cell coverings appeared near the base of the odontoblastic layer (fig. 7). The axon exhibited characteristic features common to nerves in the central pulpal tissue with uniformly distributed neurofilaments, infrequent small mitochondria with sparse cristae, and small, peripherally situated microvesicles. These small fibers frequently appeared isolated and independent of blood vessels. It was difficult to make positive identification of the small nonmyelinated fibers in the lateral intercellular spaces between odontoblasts since slender extensions of the odontoblasts appeared similar in structure to the small naked axons (fig. 7).

By 19 days a subodontoblastic nerve plexus was clearly evident and by 25 days, nonmyelinated branches of nerves from the subodontoblastic plexus extended immediately subjacent to the odontoblastic layer, but the identification of Schwann cell covered or naked axons between odontoblasts was not possible. However, a few morphologically distinct neural elements which represented their most peripheral extension revealed microvesicles, small dark granular bodies with internal concentrally occurring forms and isolated multivesicular bodies (figs. 8, 9). These nerves were separated from the odontoblastic process by a submicroscopic space of 200-250 $\AA$ and were easily distinguished from the adjacent odontoblastic processes which appeared nearly organelle-free by 25 days and contained occasional micro- 
vesicles, microtubules or dark granular bodies. They also appeared devoid of mitochondria and their processes were characterized by numerous fine longitudinally arranged filaments.

From 30 to 50 days, intratubular nerves extended into the dentin in clusters of several nerves in contrast to the infrequent nerves in the predentin at 25 days. Although the number of intratubular nerves increased with age, their morphology remained similar to that observed in the predentin of the younger specimens (fig. 10).

At 35 days the nerves of the plexus contained both myelinated fibers and small nonmyelinated axons most of which retained a Schwann cell covering (fig. 11). Several bundles of nerve fibers within the plexus appeared closely adjacent to small capillaries consisting of several endothelial cells separated from the surrounding connective tissue by a wide basement membrane. A continuous basement membrane surrounded the layer of pericytes of these capillaries and maintained a separation between nerve fibers and capillary wall (fig. 11).

By 50 days, the intratubular nerves in the dentin overlying the tips of the pulpal horns could be traced directly as far as $80 \mu$ toward the dentino-enamel junction. In the areas where clusters of intratubular nerves were present, they were observed at low magnification to occupy at least $10 \%$ of the dentinal tubules, but in many areas, the tubules were devoid of any nerves. Only an occasional isolated intratubular nerve could be traced into the predentin and dentin of the pulpal walls lateral to the tip of the pulp horn. In longitudinal sections of odontoblastic processes where intratubular nerves could be observed, they appeared to exhibit areas of dilation and constriction (fig. 12).

The changing relationship of nerve to odontoblast was obvious at 50-60 days when Schwann cell covered axons were observed intercellularly among adjacent odontoblasts (fig. 13), and a few free axons appeared to extend among the odontoblasts to the odontoblastic-predentinal border. Free axons were easily identified when observed longitudinally since their contents included long delicate neurofilaments, peripheral microvesicles and small mitochondria located at their bulbous terminations at the odontoblastic-predentinal border (fig. 14). Free axons were separated from the body or process of adjacent odontoblasts by a rather uniform submicroscopic space of approximately $200 \AA$.

By 60 days, extensions of the Schwann cell covered axons were observed in the predentin at the cuspal tip (fig. 15). The morphology of these nerves was similar to comparable axons located both pulpally and intercellularly among adjacent odontoblasts. The slender processes of the Schwann cell surrounding the small, ovalshaped axons were separated by a small submicroscopic space at the mesaxon.

The relationship of the odontoblast and adjacent nerve fibers changed gradually from 25 to 70 days due to the nerves appearing deeper in the dentin. This was a result of apposition of dentin. The structure of the several segments of nerves located in the predentin at 25 days appeared the same as those embedded deeper in the dentin at 70 days (fig. 16). The Schwann cell covered and free axons located intercellularly among odontoblasts and subsequently in the predentin closely resembled nonmyelinated and naked axons located in the subodontoblastic plexus (fig. 11).

\section{DISCUSSION}

Both light and electron microscopic techniques used in this study revealed that the penetration of nerves into predentin and dentin occurs after the eruption of the tooth. These observations are similar to the developmental pattern of pulpal nerves in humans noted by Arwill ('58), Fearnhead ('63, '67), and Bernick ('64). Fearnhead ('63, '67) reported that the subodontoblastic neural plexus did not appear until root formation was complete, at which time very few nerves were found in predentin and only rarely in dentin. Since a significant amount of coronal dentin had been laid down prior to the incorporation of nerves into dentinal tubules, subsequent peripheral extension of nerves into dentin is dependent upon the mechanism of their entry into developing dentin.

Fearnhead ('67) has suggested two possible modes of entry of nerves into den- 
tinal tubules: either the nerve fibers become entrapped in predentin as it develops or by peripheral growth of the axons once entrapped in the tubules. Although Fearnhead favored the concept of axonal growth, our ultrastructural findings indicate that a close relationship is established between intratubular nerves and the odontoblastic process following initial incorporation in the dentinal tubule. (fig. 9). This would permit minimal peripheral extension of the nerve after its initial entrapment in predentin. Additional deposition of peritubular dentin further restricts the diameter of the dentinal tubules (Symons, '67), thereby decreasing the space available for the peripheral extension of the intratubular nerves. Finally, if intercellular attachments between intratubular nerves and odontoblastic processes are present, they would further limit axonal extension peripherally. The presence of intercellular attachments between these nerves and odontoblastic processes was reported by Frank ('68a,b) as complex infoldings with fusion of the outer leafiets of their plasma membranes, a relationship which characterizes tight junctions as first described by Farquhar and Palade ('63).

Frank ('68b) also reported that intradentinal nerves pursue a spiral course around the odontoblast process in their most peripheral location. The constrictions and dilations along the course of the intratubular nerves noted in this study do not support the concept of spiraling (fig. 12). On the other hand, the dilations and constrictions resemble more closely the "beaded" nerves seen in the light microscope by Sosa and Stella ('57). This interlocking relationship of the intratubular nerve and accompanying odontoblastic process would tend to limit peripheral axonal growth.

The distance that intratubular nerves extend into human dentin was reported by Fearnhead ('57) who was able to trace intratubular nerves only $0.4 \mathrm{~mm}$ into inner dentin. He stated that terminal nerve fibrils too small to be identified by the optical microscope may extend to the dentino-enamel junction as continuations of the nerves observed in predentin and inner dentin. Fearnhead ('57, '61) suggested that the increased resolving power of the elec- tron microscope might clarify the true character of small silver stained fibrils which he observed in the dentinal tubules near the dentino-enamel junction. Our ultrastructural observations of the full depth of dentin in mouse molars revealed that intratubular nerves were limited to the circumpulpal dentin. Utilizing the electron microscope, Frank ('68b) reported intratubular nerves only in the inner dentin of human molars and recently, Tsatsas and Frank ('72) observed that no nerve endings appeared in the outer coronal dentin. In view of these ultrastructural observations of the location of intratubular nerves, it may be concluded that intratubular nerves are limited to the inner dentin and do not extend to the dentino-enamel junction.

Fearnhead ('57) reported the distribution of intratubular nerves in the dentin of mature human teeth. In this study, he attempted to quantitate such nerves in several locations of coronal and radicular dentin. He reported intratubular nerves in less than $10 \%$ of the tubules in the region just lateral to the pulp horn as compared to less than $1 \%$ at the level of the cementoenamel junction, and found only occasional nerves in radicular dentin. Intratubular nerves appeared limited to the inner dentin since Fearnhead could not verify nerves farther than $0.4 \mathrm{~mm}$ from the pulp. The location of intratubular nerve endings in our ultrastructural observations of mouse molars revealed them to be predominately in the region of the pulp horns. In terms of developmental stages, when the tooth had reached functional occlusion, the endings were usually located in clusters in adjacent or nearby dentinal tubules overlying the pulpal horns (fig. 10) where the ratio of nerves to odontoblasts approached one to ten. This observation is in marked contrast to the $42.5 \%$ reported by Arwill ('67) of "associated cells" in human predentin. However, Arwill's observations in predentin were based on counts where only 40 odontoblastic processes were included, which may have been influenced by a count involving a cluster of nerves. In the present study, the dentinal tubules lateral to the cuspal regions were frequently devoid of intratubular nerves. Thus there seems to be 
considerable agreement that intratubular nerves are not distributed generally throughout the dentinal tubules of coronal or radicular dentin.

Our ultrastructural observations of the morphology of intratubular nerves in mouse molars agrees substantially with the reports of similar structures in humans by Frank ('66a,b '68a,b) and Arwill ('67, '68). The identification of intratubular nerves in mouse molars was aided by noting the similarity of their fine structures to that of free corial endings, free epithelial endings (Cauna, '66) and intraepidermal specializations (Munger, '65). Each of the latter morphologically distinct nerve endings share with intratubular endings such structural properties as accumulations of mitochondria, numerous microvesicles, and granules of varying size and density (Cauna, '66). Frank ('68b) reported that intratubular nerves could be identified by characteristic cellular components, and he suggested that it was valid to identify a nerve fiber with the electron microscope without awaiting collaborating experimental evidence. Frank stated, however, that such evidence could strengthen the identification of intradentinal nerves. Such experimental evidence has been provided by Corpron et al. ('72) in mandibular molars of mice in which the inferior alveolar nerve was sectioned for a period of 21 days. After resection, small Schwann cell covered axons located at the odontoblastic-predentinal junction exhibited marked degeneration of the axons. Similar nerves in comparable locations in the control specimens revealed no evidence of degeneration.

The function of the intratubular nerves has been described to be sensory by Frank ('66a,b).He concluded that such intradentinal receptors in combination with the odontoblastic process represented a unique type of neurosensitive complex, but the question of continued viability of entrapped intratubular fibers was raised by Arwill ('60, '63). He postulated that envelopment by "secondary predentin" and mineralization of the predentin caused the enclosed nerve fibrils to appear to decompose, which might subsequently result in their loss of function. Several factors must be considered in the evaluation of continued viabil- ity. First, the intratubular nerves noted in this study closely resemble functional free endings such as in the epithelium of the skin (Cauna, '66; Munger, '65). Second, our observations of entrapped nerves revealed no significant morphological differences among nerves of various ages and depths of entrapment in dentin. Third, a study of the changes in the intratubular nerve endings after inferior alveolar nerve resection has been made (Corpron et al., '72) and no similarity exists between the ultrastructure of resected nerves and the structures described in this study.

Stockinger and Pritz ('70) deny the existence of "pain nerves" in human dentin. They believe painful stimuli pass from odontoblast to bipolar cells to the nerves. Present observations in the mouse clearly show the presence of intratubular nerves; however, the bipolar cells were not identified.

In the final analysis, the observations of this study have revealed an intimate relationship between odontoblastic processes and the terminal portion of the intratubular nerves which remains essentially unchanged throughout the life of the tooth. However, with the continuous apposition of dentin, the cell body of the odontoblast moves pulpally and its process lengthens to compensate for this deposition. In order for the terminal portion of the intratubular nerve to maintain a stable relationship with the odontoblastic process, the more proximal aspect of nerve must either grow in length or more of the pulpal segment of this nerve must be incorporated into the dentinal tubules as they increase in length. Both of these possibilities are worthy of consideration since in older teeth, the nerve fibers appear in dentin a further distance from the pulp. On the other hand, these intratubular nerves are located no closer to the dentino-enamel junction in the older tooth than they were at the time of their initial incorporation into dentin. This leaves the entire area of more peripheral dentin devoid of intradentinal nerves. The only vital tissue in the dentinal tubules extending to the dentino-enamel or dentinocemental junction is the odontoblastic processes. Thus it is important to consider these processes and their side branches in the role of transmission of stimuli through 
the peripheral dentin to intratubular nerves in inner dentin.

\section{ACKNOWLEDGMENTS}

We wish to thank Drs. James R. Smalley and Soo Duk Lee for their technical assistance during this investigation.

\section{LITERATURE CITED}

Arwill, T. 1958 Innervation of the teeth. Trans. Sch. Dent. (Stockholm and Umea), 2: 33-88. 1960 The significance of the innervation of the predentine. Oral Surg., Oral Med., and Oral Path., 13: 743-749.

1963 Some morphological aspects of the dentinal innervation. In: Sensory Mechanisms in Dentine. D. J. Anderson, ed. Pergamon Press, New York, pp. 3-14.

1967 Studies on the ultrastructure of dental tissue. II. The predentine-pulpal border zone. Odont. Revy., 18: 191-208.

1968 The ultrastructure of the pulpodentinal border zone. In Dentine and Pulp; Their Structure and Relations. N. B. B. Symons, ed. Livingston, London, pp. 147-167.

Bernick, S. 1959a Innervation of the developing molar teeth of rats. Anat. Rec., 133: 91-103. $1959 \mathrm{~b}$ Innervation of the teeth and periodontium. Dent. Clinics N. Amer., n.v.: 503-514

1964 Differences in nerve distribution between erupted and non-erupted human teeth. J. Dent. Res., 43: 406-411.

Cauna, N. 1966 Fine structure of the receptor organ and its probable functional significance. In: Touch, Heat and Pain. A. S. V. de Reuck and J. Knight, eds. Churchill, London, pp. 117-127.

Corpron, R. E., J. K. Avery and C. F. Cox 1972 Ultrastructure of intradentinal nerves after resection of the inferior alveolar nerve in mice. J. Dent. Res., 51: 673.

Farquhar, M. G., and G. E. Palade 1963 Junctional complexes in various epithelial. J. Cell Biol., 77: 375-412.

Fearnhead, R. W. 1957 Histological evidence for the innervation of human dentine. J. Anat., 91: 267-277.

1961 The neurohistology of human dentine. Proc. Roy. Soc. Med., 54: 877-884.

1963 The histological demonstration of nerve fibers in human dentine. In: Sensory Mechanisms in Dentine. D. J. Anderson, ed. Pergamon Press, New York, pp. 15-24.

1967 Innervation of dental tissues. In: Structural and Chemical Organization of Teeth,
Vol. I. A. E. W. Miles, ed. Academic Press, New York, pp. 247-281.

Frank, R. M. 1966a Etude au microscope electronique de l'odontoblaste et du cannicule dentinaire humain. Arch. Oral Biol., 11: 179-199. - $1966 \mathrm{~b}$ Ultrastructure of human dentin. Third European Symposium on Calcified Tissues. Springer-Verlag, Heidelberg, pp. 259-272. 1968a Attachment sites between the odontoblast process and the intradental nerve fiber. Arch. Oral Biol., 13: 833-834.

1968b The ultrastructural relationship between the odontoblast, its process and the nerve fibre. In: Dentine and Pulp; Their Structure and Relations. N. B. B. Symons, ed. Livingston, London, pp. 115-145.

Johansen, E. 1967 Ultrastructure of dentin. In: Structural and Chemical Organization of Teeth, Vol. II. A. E. W. Miles, ed. New York, Academic Press, pp. 35-74.

Kerebel, B. 1964 Innervation de la prédentine humaine. Actualités Odonto. Stomat., 18: 181.

Kubota, K., J. Kubota and J. Kuroe 1960 A contribution to the problem of dentin innervation in man. Okjimas Fol. Anat. Jap.: 34: 419447.

Munger, B. L. 1965 The intraepidermal innervation of the snout skin of the opossum. J. Cell Biol., 26: 79-97.

Rapp, R., J. K. Avery and R. A. Rector 1957 $A$ study of the distribution of nerves in human teeth. J. Canadian Dent. Assoc., 23: 447-453.

Rowles, S. L., and E. B. Brain 1960 An improved silver method for staining nerve fibers in decalcified sections of teeth. Arch. Oral Biol., 2: $64-68$.

Sosa, J. M., and A. P. Stella 1957 Investigaciónes sobre la fina inervación dentaria. An Fac. Odont., 3: 81-125.

Stella, A. P., and A. Fuentes 1965 Inervación dentinaria intracanalicular. Su demonstración por el método de la hematoxilina-férrica de Heidenhain. Universidad de los Andres, Facultada de Odont. Merida-Venezuela, 63p.

Stockinger, V. L., and W. Pritz 1970 Morphologische Aspekte der Schmerzempfindung im Zahn. Dtsch. Zahnärztl. Z. 25: 557-565.

Symons, N. B. B. 1967 The microanatomy and histochemistry of dentinogenesis. In: Structure and Chemical Organization of Teeth. Vol. I. A. E. W. Miles, ed. Academic Press, New York, pp. 275-324.

Tsatsas, B. G., and R. M. Frank 1972 Ultrastructure of the dentinal tubular substances near the dentino-enamel junction. Calc. Tiss. Res., 9: 237-242. 


\section{Abbreviations}

A, Axon

BM, Basement Membrane

D, Dentin

EC, Endothelial Cell

ER, Endoplasmic Reticulum

F, Fibroblast

M, Mitochondria

MNF, Myelinated Nerve Fiber
NF, Nonmyelinated Nerve Fiber

OD, Odontoblast

OP, Odontoblastic Process

P, Pulp

PC, Pericyte

PD, Predentin

RBC, Red Blood Cell

SC, Schwann Cell

\section{PLATE 1}

\section{EXPLANATION OF FIGURES}

1 Fifth day of age. Nerve fibers and blood vessel extending from the central to the peripheral pulp (P). No nerves are present in the odontoblastic layer at this age. Dentin (D) and predentin (PD) have already developed. Silver cyanate stain. $\times 288$.

2 Ninth day. Branches of a large nerve trunk extend from the pulp horn and reach the odontoblastic layer (OD) at this age. Silver cyanate stain. $\times 288$.

3 Fifteenth day. A few branches of a nerve trunk have now penetrated the odontoblastic cell layer (OD). Silver cyanate stain. $\times 288$.

4 Twenty-fifth day. The mesial horn of the first molar with a large neurovascular bundle extending into the pulp horn. Extensive branching of the nerve trunk can be seen in the pulp horn with the fibers within the odontogenic region. An increased number of nerve fibers are seen forming a subodontoblastic nerve plexus at this age. Silver cyanate stain. $\times 288$.

5 Twenty-fifth day. Nerve fibers originating from the subodontoblastic plexus extend between the odontoblasts and loop into the predentin (PD). Several other isolated nerves can be observed coursing into the predentin and possibly into dentinal tubules. Silver cyanate stain. $\times 720$.

6 Fiftieth day. A cluster of nerves originating from the dense subodontoblastic plexus now course between the odontoblasts and continue into and through the predentin (PD) and into the adjacent calcified dentin (D). Silver cyanate stain. $\times 720$. 
ULTRASTRUCTURE OF NERVES IN TEETH

PLATE 1

Richard E. Corpron and James K. Avery
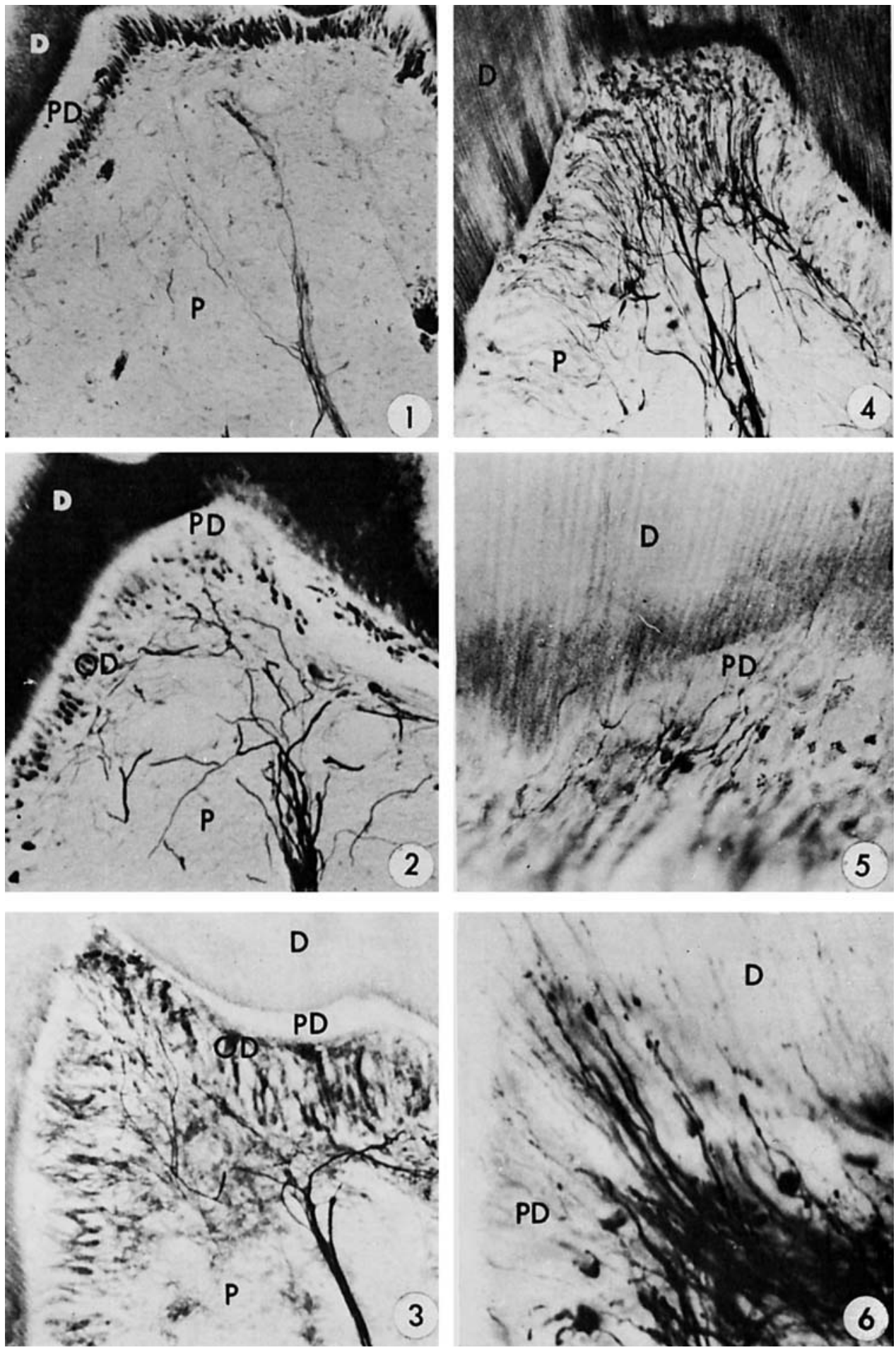


\section{PLATE 2}

EXPLANATION OF FIGURES

7 A small nerve is located among cellular processes of the subodontoblastic layer just basal to several odontoblasts (OD) in a nine day old tooth. The nerve contains a central axon (A) with one mitochondrion (M), several small vesicles and neural fibrils, and is covered by a Schwann cell (SC). $\times 23,000$.

8 Twenty-five days. A section in the predentin (PD) exhibits three odontoblastic processes (OP) cut in cross-section. At the left, there appears a small portion of calcified dentin (D). In the upper right, a small nerve fiber (NF) accompanies an odontoblastic process separated by a small space 200-250 $\AA$ wide. Internally, the nerve fiber exhibits several centrally located mitochondria and numerous small vesicles and dark granules interspersed throughout the structure of the fiber. $\times 30,000$. 

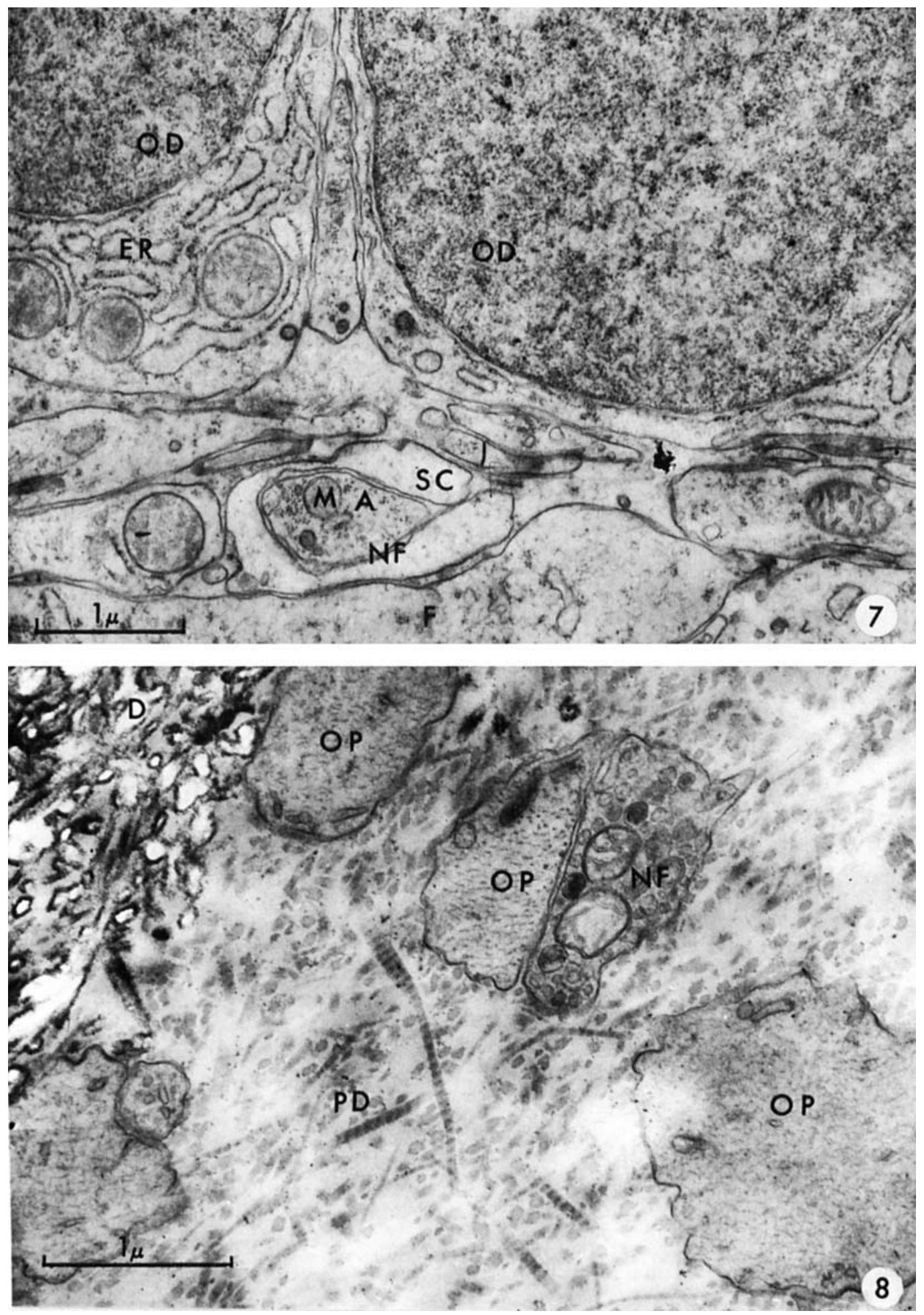
PLATE 3

EXPLANATION OF FIGURES

9 Twenty-five days. A nonmyelinated nerve (NF) appears in a zone of calcified dentin (D) accompanying an odontoblastic process (OP). The nerve exhibits a distinct plasma membrane and contains numerous organelles. An area of predentin (PD) appears between two odontoblastic processes (OP). $\times 21,000$.

10 Thirty days. A view of the predentin (PD) with several odontoblastic processes (OP) in cross-section. Three small nerves (NF) are located adjacent to, but separated from, odontoblastic processes by a narrow space. The internal structure of the nerve endings reveals membranebound structures which vary in size and content, numerous small vesicles with occasional dark contents, and larger vesicles with dark contents and lamellar-like structure. $\times 21,000$. 

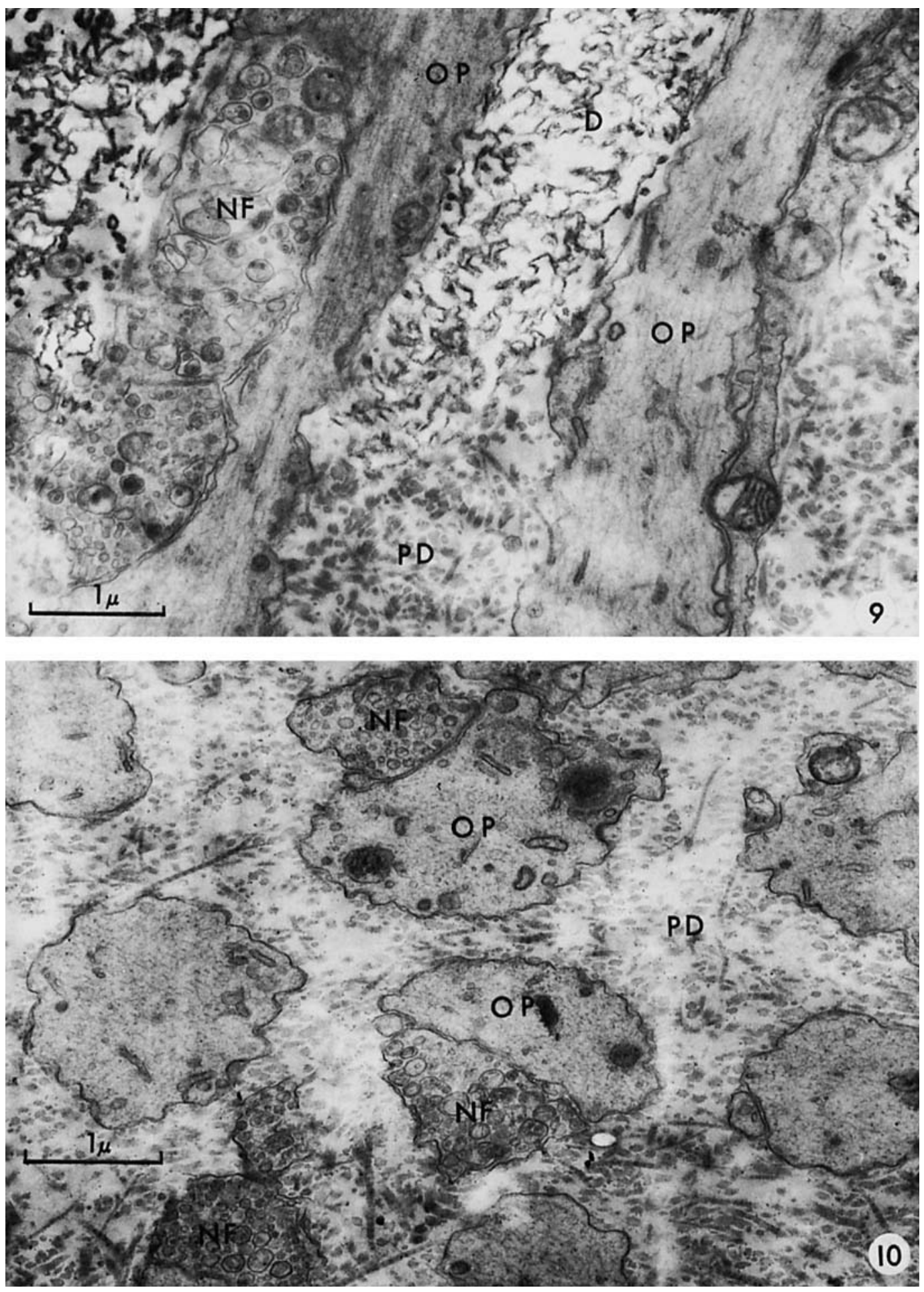
PLATE 4

EXPLANATION OF FIGURE

11 Thirty-five days. The area is from the subodontoblastic plexus at the pulp horn. Both myelinated (MNF) and nonmyelinated nerves (NF) are closely associated in clusters and usually have a Schwann cell covering (SC). A large capillary containing a red blood cell (RBC) exhibits an endothelial cell lining (EC) surrounded by a distinct basement membrane (BM) which, in turn, is surrounded by pericytes (PC). The axons of both types of nerves contain similar contents: numerous neural filaments, occasional mitochondria, and sparsely distributed small microvesicles near the periphery of the axon. No nerves are in direct contact with the capillary wall. $\times 14,000$. 


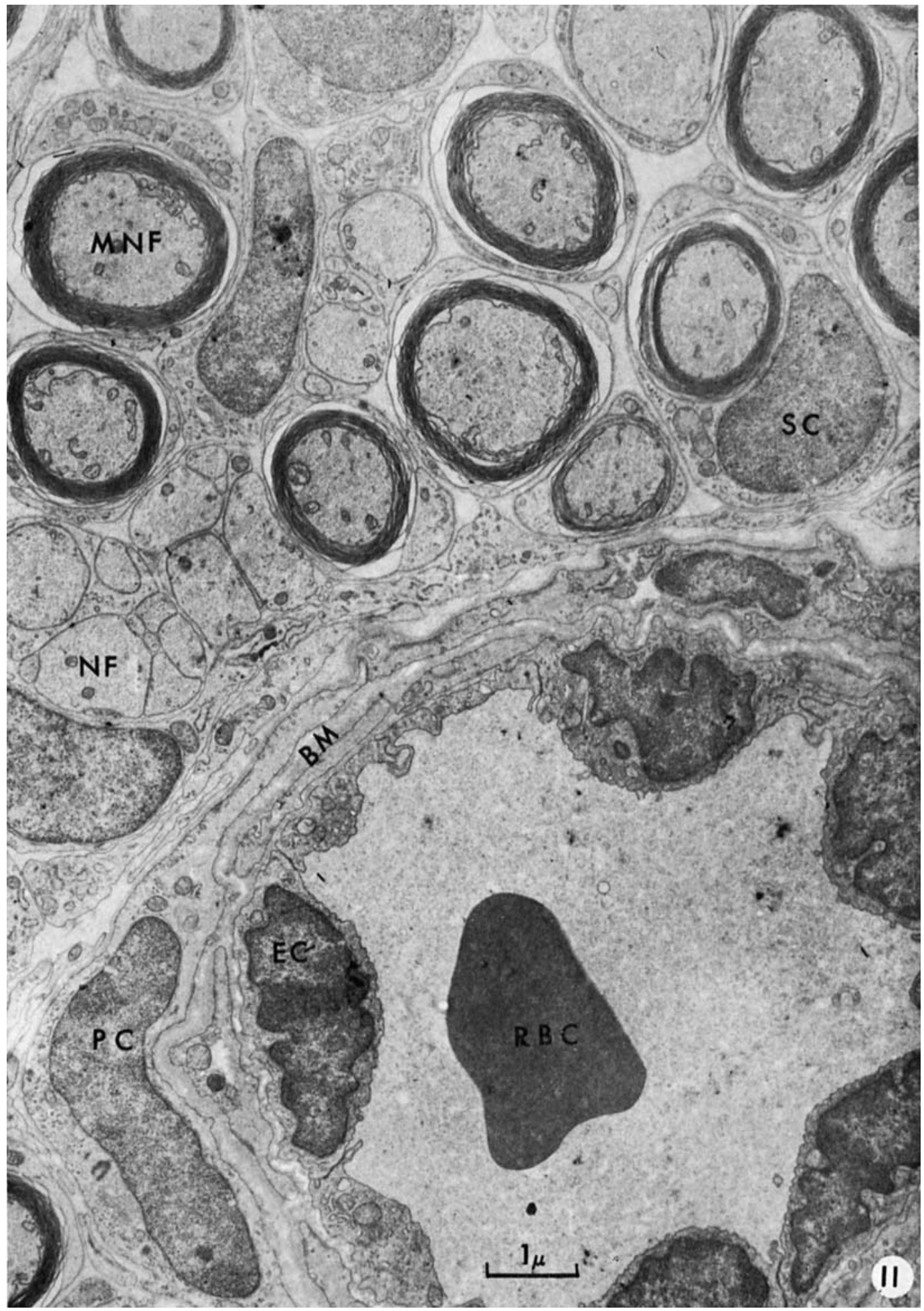


PLATE 5

EXPLANATION OF FIGURE

12 Fifty days. A longitudinal section of several odontoblastic processes which appear in the calcified dentin (D). Note the area of predentin (PD) in the lower left corner of the photograph. Nerve fibers (arrows) are observed in several dentinal tubules accompany the odontoblastic processes (OP). Dilations and constrictions appear along the length of the nerves. $\times 5,400$. 
Richard E. Corpron and James K. Avery

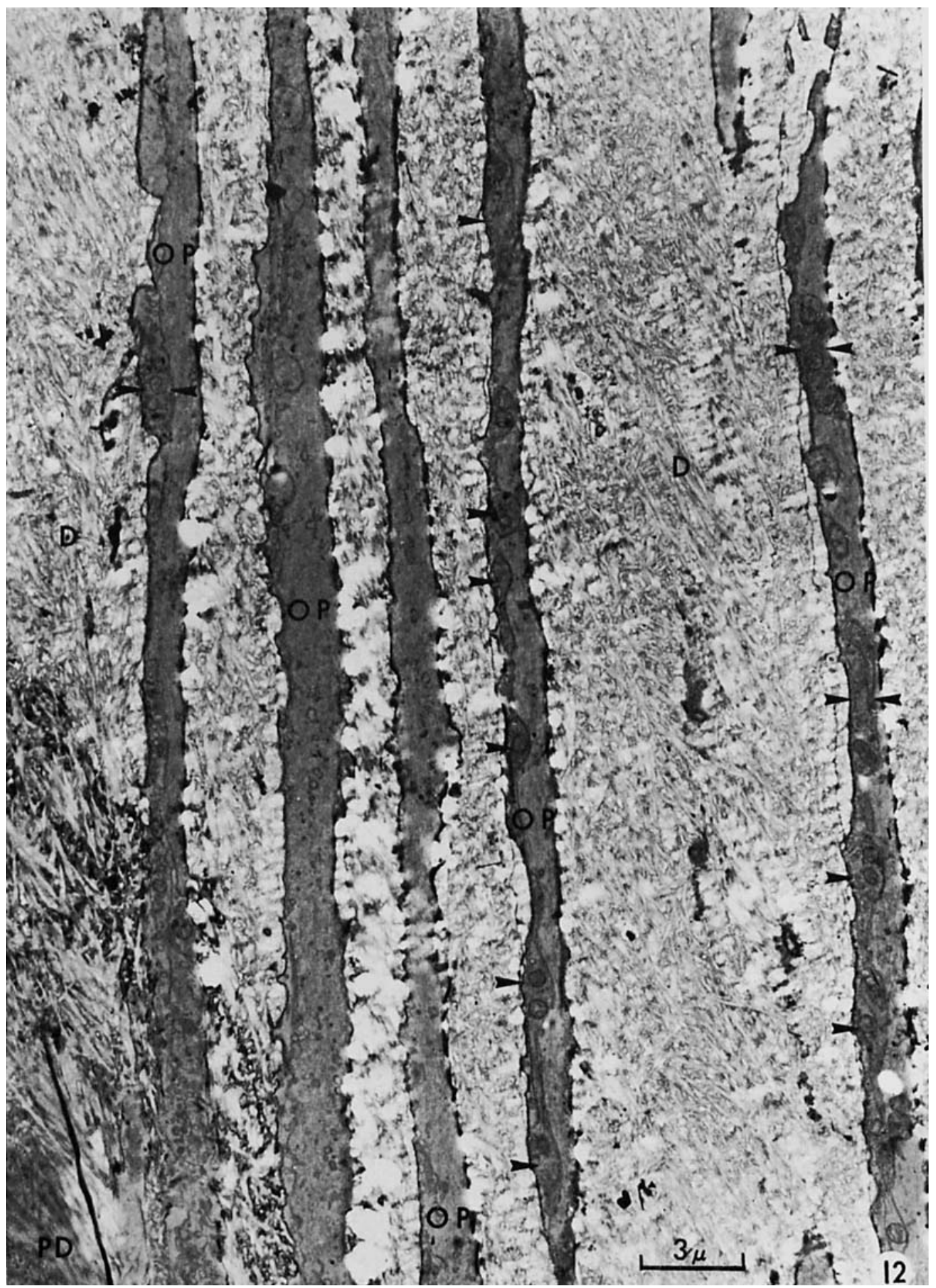


PLATE 6

EXPLANATION OF FIGURES

13 Fifty days. A small nonmyelinated nerve fiber (NF) with a Schwann cell covering is observed between two odontoblasts (OD) in a tangential section through the odontoblastic layer overlying a pulpal horn. The thin layer of predentin (PD) shows signs of mineralization. $\times 21,000$.

14 Fifty-five days. A small, nonmyelinated nerve fiber (NF) without a Schwann cell covering is observed in longitudinal section between adjacent odontoblasts (OD) overlying a pulpal horn. A dilation along the course of the nerve appears in close proximity to the predentinal surface (PD). Within the nerve, there are longitudinally oriented fine neurofilaments, occasional peripherally located microvesicles, and several mitochondria. $\times 21,000$. 

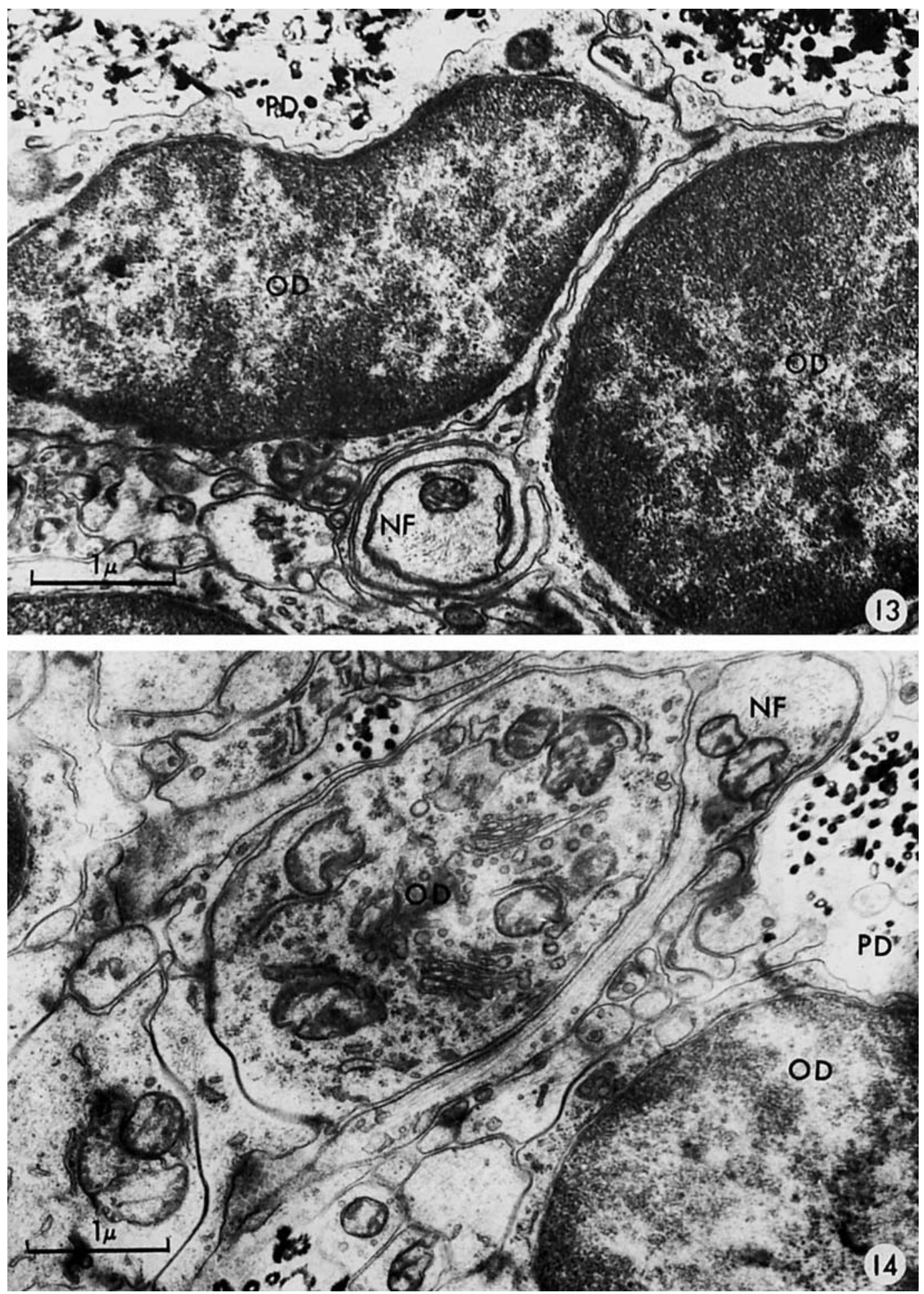
PLATE 7

EXPLANATION OF FIGURES

15 Sixty days. A small nonmyelinated nerve (NF) with a Schwann cell covering (SC) is located in the predentin (PD) overlying the pulpal horn. The centrally located axon (A) contains a mitochondrion (M) and several vesicles. $\times 25,000$.

16 Seventy days. A nonmyelinated nerve (NF) is located intratubularly with an accompanying odontoblastic process (OP) in the dentin (D) overlying the pulpal horn. The nerve contains several mitochondria (M) and numerous small vesicles and granules. At the right, there appears a structure (arrows) similar in morphology to the odontoblastic process which appears adjacent to the process. Such a structure may represent a lateral branching from the odontoblastic process. $\times 25,000$. 
Richard E. Corpron and James K. Avery
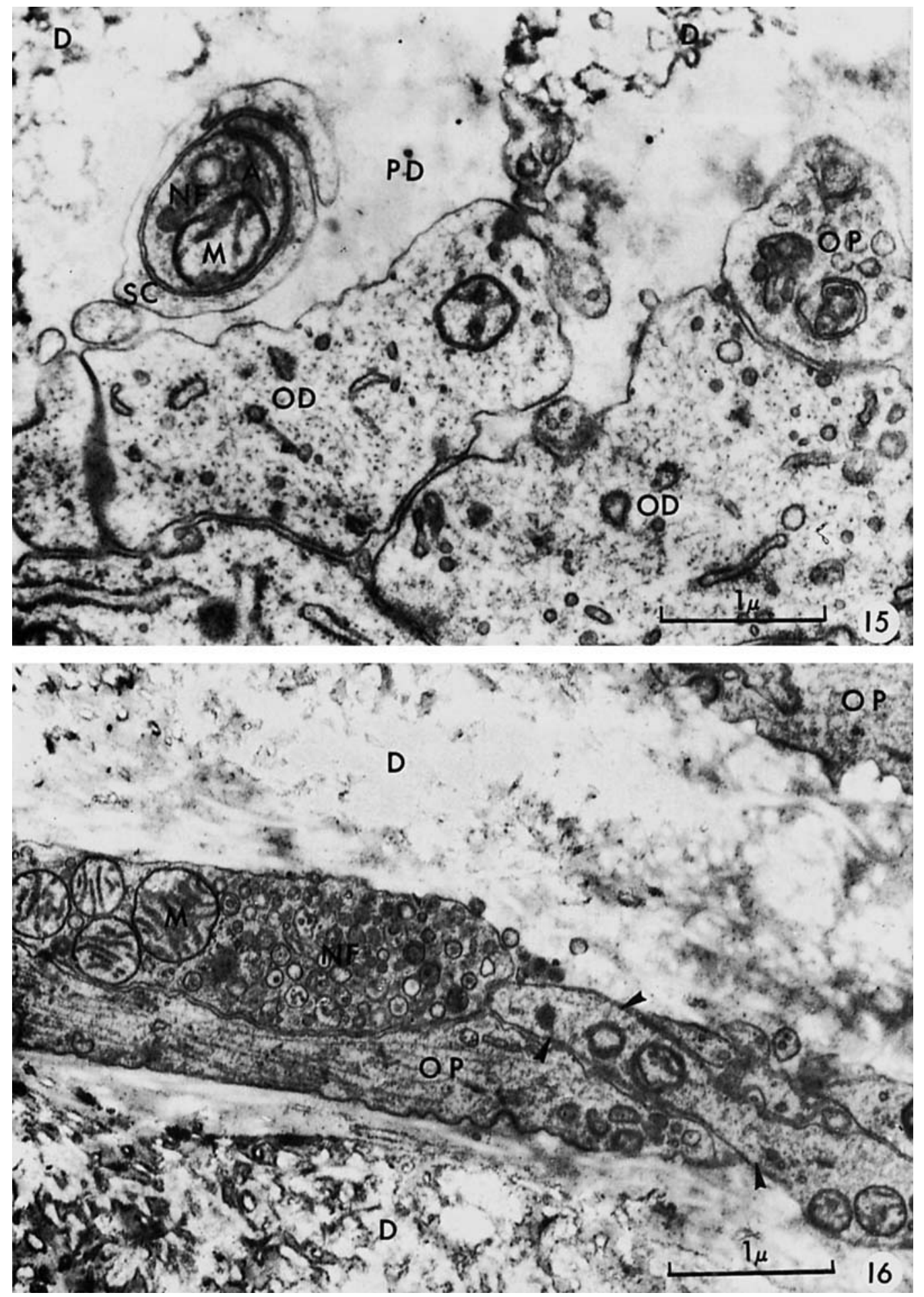